\title{
CHOOSING BETWEEN TRAM AND METRO IN HONG KONG - UTILITY, AFFECT AND DEMOGRAPHICS
}

\author{
WENHAN YANG ${ }^{1} \&$ JOHN ZACHARIAS ${ }^{2}$ \\ ${ }^{1}$ Civil Engineering Department, The University of Hong Kong, HKSAR, China \\ ${ }^{2}$ College of Architecture and Landscape, Peking University, China
}

\begin{abstract}
A major question facing many cities is whether to give preference to surface light rail or to heavier rail underground. In theory, the two systems have quite different functions because of average travel speed, and integration with local land use and surface movement systems. There are differences in headways, capacity, and station density, although these differences can be lessened through technological advances. The major implication for city development is the impact that these two systems have for surface development. In general, metro systems favour nodal development, often in the form of transit-oriented development (TOD), while tramways support more linear development, with direct support for street-oriented commerce. In Hong Kong, the recent extensions to the Island Line parallel the alignment of the surface tramways. In this study, we apply a structured questionnaire to local residents to determine how and when they use each of these services. Preference for tram increases for short-distance trips and overall for individuals over the age of 50. For short trips of 2-3 km, travel time, travel cost, waiting time, air conditioning, service quality and vehicle stability were all significant in the preference for metro. Scenery, emotional attachment, gender and age were all significant in the choice of tram for those same trips. Passengers paid little attention to the longer access times to metro and believed that waiting time was less, although access and waiting time are both longer for the metro mode. There was less distinction between the modes for longer trips, in part because of the smaller number, in part because of the adherence of elderly people to the tram mode. In Hong Kong, the two modes are perceived differently and serve somewhat different clienteles, which may be important for the operators of these systems as they consider the integration of surface and underground transit.

Keywords: mass rapid transit, tramway, light rail transit, modal split, Hong Kong, travel experience, travel choice.
\end{abstract}

\section{INTRODUCTION}

It is widely assumed that the introduction of the relatively expensive underground metro system entails the re-use or abandonment of existing surface public transport systems. In many instances, bus lines are reconfigured to serve as feeder systems for the metro. Transit-oriented development (TOD) has received much attention worldwide in the development around metro stations, to facilitate walking access to the station. In general, it is widely assumed that the higher travel speed of metro will render existing surface modes redundant or obsolete, at least for destination areas within walking access of stations at both ends of the trip. This utility-based concept has prevailed in metro system planning for a very long time, yet there are reasons to question its universality.

Other studies of transit combinations provide insights into traveller considerations in the choice or preference for a particular mode, which we explore below, before presenting our empirical study of a metro-tram combination. The tram system in Hong Kong now parallels the Mass Transit Rail (MTR) system in the city which, to our knowledge, is a unique combination of surface and underground rail systems on a single corridor (figure 1). Given widespread preference for rail systems over bus systems, this case provides a unique opportunity to understand how one rail system is perceived and used compared with another, for very similar origins and destinations. The implications for mass urban transit planning go well beyond this particular case, as planners worldwide grapple with the choice between 


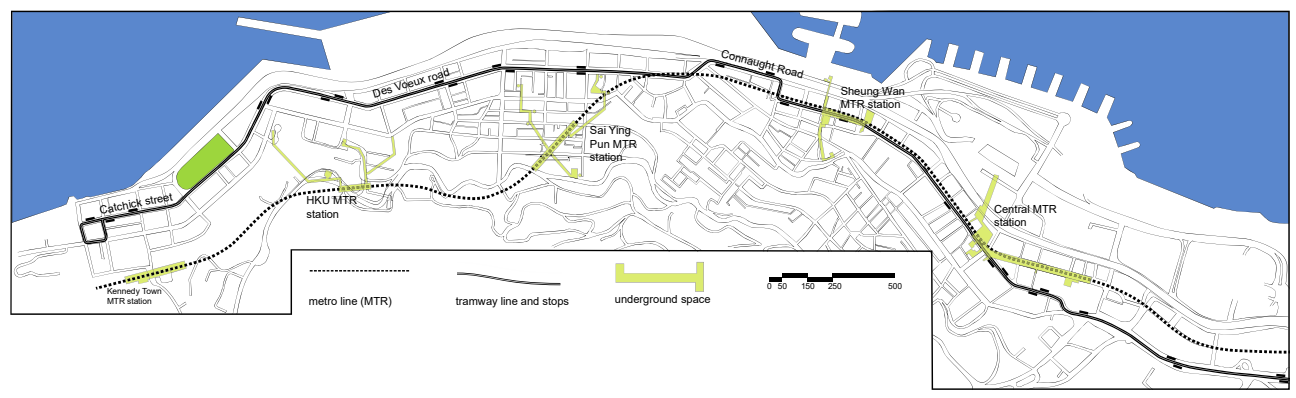

Figure 1: The MTR and Tramway lines in the Western District, Hong Kong Island.

surface rail systems of various kinds and a more standardized underground rail model.

In addition, the effort to capture a high proportion of potential travellers within a presumed walking buffer could benefit from better understanding of what attracts users to other modes.

The following review of findings on multiple mode transit corridors includes the following topics: public impressions of urban rail and the general effects of the implementation of urban rail in cities; impressions of rail; factors influencing the choice of rail-based public transit over other modes; access to underground and surface modes. We also include a brief review of utility function as related to public transport. The purposes of this review are firstly to understand complementary and competing factors in the provision of parallel public transit systems. Secondly, we are looking specifically for those human factors likely to intervene in the present choice model, based on empirical evidence in other cases. Thirdly, we would like to see how these fairly recent developments in public transit planning relate to the more standard treatments within the utility framework.

\subsection{The worldwide growth of urban rail}

Light rail has seen rapid growth in developed and developing countries in recent years, in an effort to cope with urbanization and with motorization of urban travel. In 2015 there were 388 light rail systems worldwide [1], with the total continuing to increase. One key reason for this growth is said to be system reliability [2], with delays and shutdowns extremely rare, in the context of increasing time uncertainties in urban travel in most cities worldwide. At the same time, technical innovations have raised the capacity of such systems so that they can often compete with heavier rail alternatives.

The urban development potential of light rail has been highlighted by many, with some suggesting that new alignments in built up areas offer development opportunities and a synergistic relationship with local urban activity. The resurgence of such systems in countries such as Turkey provide evidence of many positive spin-offs [3]. The recently built system in Tunis offers high ridership, cost recovery and access to the central area, while representing some challenges for development at the regional scale [4].

In Mainland China, there are 42 cities currently growing metro systems, most of them in second and third tier cities. The literature remains divided on the conditions for the implantation of metro or surface light rail. In general, in China, the underground metro has been favoured as having no impact on motor traffic on the surface, while eventually capturing high passenger volume. It is generally accepted that surface light rail favours linear urban development because of quick access and more closely placed stations, while the metro favours nodal development, around and above the station. 
In this paper, we are concerned with the tramway, or streetcar system, which always travels at lower speeds than the metro, has more frequent stops and shares street space with motor vehicles. The particular case is the historic Hong Kong tram, which we present below. We also consider the recent extension of the MTR Island Line on the same corridor, also discussed below.

\subsection{Public preference for the tram}

There is an accumulating literature on public preference for surface rail modes over bus systems. Although there is no comparable literature on rider preference for surface or underground rail, it is useful to examine the rail-bus comparisons for understanding why surface rail might not be entirely replaceable with underground metro.

When faced with visualizations of tram and bus rapid transit (BRT), people have a generally more positive impression of the rail-based system, even though the BRT runs on its own right-of-way and may have speed advantages over rail [5]. Experience with tram will lead to a more favourable response, but higher incomes and age also play in favour of rail.

It is also often thought that the tram is cleaner, while most bus systems operate on internal combustion engines. When compared with bus systems, surface rail is thought by stakeholders to offer better accessibility and intermodality [6]. In these and other studies, local users often associate a tram system with better management, which in a number of studies cited below, has proved to be an important factor in mode choice. Customer experience factors figure prominently in the decisions to replace or augment existing roadbased public transit [7]. However, such positive perceptions of rail may be highly conditioned by public involvement in the decision [8]. In Hong Kong, a proposal by a retired government planner to scrap the historic tram system paralleling the MTR was met with a flood of criticism and community organization to protect the iconic tram.

\subsection{Utility-based approaches to public transport corridor planning}

The consideration of direct demand for public transport will favour faster modes, all else being equal, in the context of trip time minimization. In Nanjing, China, metro use overall and between stations is accurately predicted considering local residential population and employment as well as feeder systems such as shared bicycles [9]. Such findings lead to supportive policies on land use and access networks. In Hong Kong, the commercial, office and entertainment uses have a preponderant effect on peak time use of the metro (MTR) [10]. Such findings are also used to support the metro alternative over road-based systems, using travel time or cost, as the criterion. Random utility theory and decision field theory are used to support the fast rail alternative by considering the existing road-based alternatives [11]. Transport planning is often concerned with service efficiency. In the context of multiple transit systems in a single corridor, there is often concern about over-supply and the associated higher public costs of multiple systems [12]. Where buses continue to run in the same corridor as the metro, as is the case in most Mainland Chinese cities, there are various proposals for skip-stop systems and loadings by time to approach system capacity [13].

Others have suggested that surface rail systems, such as the tram, fill a gap between the bus and the metro [14]. The very different operating characteristics of these two systems leaves space for a hybrid surface alternative, at least within a heavily travelled corridor.

The exploration of transit-oriented development (TOD) approaches to local station areas tends to favour a station-centric layout of the road network and land uses for walking access [15]. Cost efficiency considerations in metro line design tend to favour more widely spaced 
stations with feeder bus systems [16]. While such approaches may enhance metro use, they do not address the wider issues of urban connectivity and the use of non-motorized modes independently of metro use.

\subsection{Travel experience and mode choice}

Finally, we consider the emerging literature on travel experience as a predictor of mode choice. While utility functions still describe much of human behaviour, there is a substantial proportion of travel behaviour that escapes utility as objectively measured. Consideration of the evaluation of travel in relation to subjective well-being have led to the development of new measurement tools, such as the Satisfaction with Travel Scale (STS) [17]. This topic is particularly relevant in the present case of the tram and metro in Hong Kong, given the strong support for the tram as discussed above, and the state-of-the-art facilities paralleling it in the MTR Island Line.

The literature generally supports the view that patrons prefer rail over bus alternatives, when travel time and cost are held constant [18]. The reasons revolve around notions of service quality and perceived management although these concepts require further exploration. Feelings of satisfaction can be related to intentions to use rail service, again all other factors being held equal [19]. The complex relationship between lifestyle choices, experiences of travel and general attitudes toward the urban environment have been found to be more salient in travel mode choice than the objective variables in discrete choice models [20]. While a great deal of design effort has focussed on the interior comfort of transit vehicles, it is also found that conditions of access to the rail or bus stop as well as the facilities at the stop played an important role in the degree of satisfaction with the service [21]. Estimated waiting time at bus stops varied considerably as a function of the provision of benches and enclosures [22]. At rail stations in Grenoble, heating and ventilation, along with other factors in comfortable waiting conditions had significant impact on perceived waiting time [23]. Apart from notable differences in how rail and bus services were evaluated within the urban area, differences have also been uncovered between males and females in Greece [24].

Important differences in the evaluation of various travel modes have been revealed for work and leisure trips [25]. Instrumental values figured more highly in work-related trips, however affective values rose considerably in importance for leisure-based trips. Of particular interest is the high level of satisfaction associated with non-motorized modes, including walking and bicycling. A similar result was recently uncovered in a stated preference study of travel choices between metro, bus, bicycle and walking in Beijing [26]. Although physical design and ticket price had minor effects on walking rates, the provision of a shared bicycle system on its own pathway had major impact on the use of the metro and the bus for trips of up to $5 \mathrm{~km}$.

We have seen that cumulative satisfaction with the service will have a major impact on mode choice. Conversely, it is also seen that the accumulation of negative experiences, including rude treatment by a driver and confusing information, may have important effects on willingness to use that particular service in future [27], [28].

All of the research on travel mode choice as a function of travel satisfaction revolves around bus, rail and to some extent non-motorized alternatives. Studies have not focussed on the potentially important differences that travel experience might have on the choice between surface rail, or tram, and an underground metro alternative. The issue could be important as cities begin to consider what to do with their existing bus services when the metro is introduced - hence the present study in Hong Kong. 
Table 1: Demographic distribution of respondents.

\begin{tabular}{|c|c|c|c|c|c|c|}
\hline \multirow{2}{*}{\multicolumn{2}{|c|}{ Gender }} & \multicolumn{5}{|c|}{ Age group } \\
\hline & & \multirow{2}{*}{$\begin{array}{l}\quad<18 \\
29 \\
(6.9 \%)\end{array}$} & \multirow{2}{*}{$\begin{array}{l}18-30 \\
63 \\
(15.0 \%)\end{array}$} & \multirow{2}{*}{$\begin{array}{l}31-50 \\
54 \\
(12.9 \%)\end{array}$} & \multirow{2}{*}{$\begin{array}{l}51-65 \\
18 \\
(4.3 \%) \\
\end{array}$} & \multirow{2}{*}{$\begin{array}{l}\quad>65 \\
45 \\
(10.7 \%)\end{array}$} \\
\hline Male & $\begin{array}{l}209 \\
(49.9 \%)\end{array}$ & & & & & \\
\hline Female & $\begin{array}{l}210 \\
(50.1 \%)\end{array}$ & $\begin{array}{l}34 \\
(8.1 \%)\end{array}$ & $\begin{array}{l}59 \\
(14.1 \%)\end{array}$ & $\begin{array}{l}67 \\
(16.0 \%)\end{array}$ & $\begin{array}{l}23 \\
(5.5 \%)\end{array}$ & $\begin{array}{l}27 \\
(6.4 \%)\end{array}$ \\
\hline TOTAL & 419 & $\begin{array}{l}63 \\
(15.0 \%)\end{array}$ & $\begin{array}{l}122 \\
(29.1 \%)\end{array}$ & $\begin{array}{l}121 \\
(28.9 \%)\end{array}$ & $\begin{array}{l}41 \\
(9.8 \%)\end{array}$ & $\begin{array}{l}72 \\
(17.2 \%)\end{array}$ \\
\hline
\end{tabular}

\section{METHODS AND MATERIALS}

\subsection{Study area and data collection}

The Western District of Hong Kong Island, covering Kennedy Town (KT) and Shek Tong Tsui (STT) areas is selected as the study location. This area is largely residential, with local commercial uses as well as educational facilities. The total residential population is 104,278 [27]. Both MTR Island Line and Tramway terminate at Kennedy Town. The area is served by 8 tram stops and 2 metro stations - Kennedy Town and HKU (Fig. 1). The Island Line extension to Kennedy Town opened in December 2014 but did not see increase in patronage in the following months. Daily ridership on the Tramway has been declining since 2009, however the decrease in the year following the opening of the MTR extension was $2.2 \%$, well below the decrease in the previous year of $8.1 \%$. The MTR extension itself saw relatively low patronage in that year, while overall numbers of travellers did not increase.

The face-to-face questionnaire was conducted using a random intercept protocol on the street in November and December $2016(\mathrm{n}=417)$. Table 1 provides the demographic breakdown of the respondents.

\subsection{Questionnaire design}

The questionnaire is in four parts. Part A asks respondents to recall their trip origins and destinations, mode choices and trip purposes in the past 7 days, as well as their residential locations in the study area. Part B asks the respondents to recall whether they took the metro or tram on their most recent trip to Sheung Wan (Fig. 1), a commercial and residential area $2-3 \mathrm{~km}$ to the east. Respondents were then asked to rate the level of importance of 12 aspects that may have influenced their travel mode decisions, using a Likert scale (1-5), 1 being the least important. These aspects are: 1-travel time; 2-travel cost; 3-walking distance; 4-waiting time; 5-provision of air-conditioning; 6-scenery en route; 7-emotional attachment to metro or tram; 8-crowdedness; 9-service quality; 10-frequency of passenger announcement; 11-mobile phone reception; 12-driving stability.

Similarly, Part C asks respondents to recall whether they took the metro or tram on their most recent trip to Wan Chai, a business and shopping destination approximately 6-7 $\mathrm{km}$ to the east from the study area, and to rate the level of importance of the same set of aspects. Part D asks basic personal particulars, including gender, age and income group. 


\section{RESULTS AND DISCUSSION}

\subsection{General travel patterns}

Respondents reported 690 trips, of which 233 were frequent trips- 4 or more trips per weekwhile 457 were infrequent trips-less than 4 . Metro is the most popular choice with $77.7 \%$ of frequent trips and $73.5 \%$ of infrequent trips made by metro; $11.6 \%$ and $16.1 \%$ made by tram for frequent and infrequent trips respectively; the remainder made by other modes. All trips are divided into short (less than $5 \mathrm{~km}$ ), medium $(5-15 \mathrm{~km})$ and long (over $15 \mathrm{~km})$. For frequent trips, short and medium trips each account for about $50 \%$, while for infrequent trips, medium trips account for $68.1 \%$ and short trips for only $25 \%$. This result is understandable as most of the frequent trips were work related, while the great majority of the infrequent trips were leisure related. This distribution matches Hong Kong's 2011 census of inter- and intra-zone movement.

\subsection{Accessibility to metro and tram}

The study area is relatively well served by public transport. Of the 419 respondents, 388 $(92.6 \%)$ live within $300 \mathrm{~m}$ of a metro exit or a tram stop, $22(5.3 \%)$ live within $500 \mathrm{~m}$ and only $9(2.1 \%)$ live more than $500 \mathrm{~m}$ from rail services (Fig. 1). However, the tram offers far more direct accessibility compared to the metro that has long walking distance from station entrances to platform in the case of HKU station. Taking walking distance to metro platform into account, respondents living within $300 \mathrm{~m}$ to rail services platforms dropped to $50.8 \%$.

Travel time to Sheung Wan from a uniform distribution of origin points within the study was calculated. Travel distance to the metro platform is $173 \%$ of distance to the tram platform. Considering the average travel time to Sheung Wan from points along the tram line, or from the two stations on the Island Line, we obtain in-vehicle travel times. Access times on foot, at an estimated average walking speed of $4 \mathrm{~km} /$ hour are estimated following the walking network. The reported peak time tram and MTR headways are 1.5 minutes and 2 minutes respectively. The resulting average travel time to Sheung Wan, not including egress time, is then 15.8 minutes for the MTR and 25.2 minutes for the tram. Of course, the tram stop is on the street while the Sheung Wan station is rather deep, requiring at least 2 minutes on a switch-back escalator to get to street level.

\subsection{Metro or tram choice for short and medium trips}

In keeping with the above analysis, we would expect that residents would prefer the tram for shorter trips and metro for longer ones, given the long access distances, especially for HKU station. Results show that a higher proportion of respondents preferred tram for shorter trips to Sheung Wan than the longer trips to Wan Chai, with metro remaining the mode of choice in both scenarios in our sample. Table 2 details the distribution.

Table 2: Distribution of mode choice for short and longer trips.

\begin{tabular}{|l|l|l|}
\hline \multirow{2}{*}{ Mode } & \multicolumn{2}{|c|}{ Destination } \\
\cline { 2 - 3 } & Sheung Wan & Wan Chai \\
\hline Metro & $251(59.9 \%)$ & $338(80.7 \%)$ \\
\hline Tram & $168(40.1 \%)$ & $81(19.3 \%)$ \\
\hline
\end{tabular}


There is no difference between males and females with respect to mode choice, however males over 50 years of age tend to use tram more frequently for shorter trips, while both males and females over the age of 65 like to use trams for shorter trips. Females over 65 years of age also prefer tram for longer trips. Income level is insignificant in the choices, although the tram is substantially less expensive than the metro. The tram charges a flat fare of HKD \$2.3 irrespective the trip distance, whereas eligible senior citizens and other persons enjoy a discounted fare of $\$ 1.2$. The metro operates on a distance-based fare system. For a typical trip from Kennedy Town to Sheung Wan and Wan Chai, the metro fares are $\$ 4.5$ and $\$ 6.7$ respectively. Eligible senior citizens and other person also enjoy a discounted fare of $\$ 2$. In consideration of the relatively short distance of trips in this study, we can only surmise that the effect of difference in fares on various income groups is not discernable, especially for those aged 65 and above where there is no actual fare difference. Table 3 summarizes the distributions across gender and age.

To investigate more deeply the factors underpinning these choices, we found that travel time (3.78), waiting time (3.56) and walking distance (3.54) are the three aspects that garnered the highest Likert scores. Least important aspects are service quality (2.83), mobile phone reception (2.68) and frequency of passenger announcement (2.16) for the shorter trips. For longer trips, the scores were basically unchanged at 2.86, 2.71 and 2.19, respectively.

For shorter trips, there are significant differences in the aspects underlying the choice between tram and metro. Air conditioning, service quality, and vehicle stability figured in the metro preference. On the other hand, travellers perceived longer waiting times for the tram although waiting times are shorter. Travellers were strongly attached emotionally to the tram. For longer trips, travel time, waiting time and air conditioning figured in the metro preference, but travellers had much stronger feelings about the scenery they could enjoy from the tram.

In general, the two travel modes are perceived differently by residents of the study area. These differences are accentuated for shorter trips. The strong preferences for the tram expressed by older people need special notice, in the context of an aging Hong Kong population. The generally much longer access times to the metro were not a major factor in the choice, although a more detailed analysis of residential location, by gender and age might reveal more specific relationships.

Although it was thought by some observers that the tram would be rendered redundant by the introduction of the Island Line extension, its introduction appears to have had little impact, if any, on the operations of the tram. The two systems operate for different clienteles, and for different purposes. Furthermore, in the case of Hong Kong, the tramway system and the metro are complementary to each other, rather than competing directly. As a legacy of Hong Kong, the tramway carries both cultural and practical meanings.

More generally, attention needs to be focussed on how such possibly complementary transit services support activity and urban development. While nodal development through the build-up of rail has been favoured worldwide, the return of non-motorized modes in particular is challenging the development models. The role of the tramway in Hong Kong as part of the effort to promote more active transport needs additional examination. In particular, the extent to which the tramway has supported the apparent vitality of the streets where it runs needs further study.

\section{CONCLUSION}

This study focussed on a travel corridor that includes a tramway and a newly introduced metro line extension. The introduction of the metro had little impact on tramway patronage. Resident respondents in the area of the extension tended to use the metro for work trips, which 
were generally longer than those taken on the tram. Those over 50 years of age were more likely to use the tram for shorter trips, although income and pricing had no impact on these choices. For trips to the nearest large commercial and business area, the metro remained the mode of choice although the time savings were on the order of only several minutes. The tram was more likely to be used for leisure-based trips than for work-based trips, although the nearest office district is 30 minutes away by tram. The two systems were perceived somewhat differently and by different clienteles. The tram was perceived as offering better scenery and a more interesting trip, with users expressing emotional attachment to this historical public transport system. The air conditioning, travel speed and service quality were seen as the main advantages of the metro. Users of the metro tended to discount the relatively long access times.

Table 3: Distribution of mode choice by demographic.

\begin{tabular}{|l|c|c|c|c|}
\hline \multirow{2}{*}{} & \multicolumn{2}{|c|}{ Shorter trips } & \multicolumn{2}{c|}{ Longer trips } \\
\cline { 2 - 5 } & Metro & Tram & Metro & Tram \\
\hline Male & $58.9 \%$ & $41.1 \%$ & $82.3 \%$ & $17.7 \%$ \\
\hline$<18$ & $60.6 \%$ & $39.4 \%$ & $79.3 \%$ & $20.7 \%$ \\
\hline $18-30$ & $71.0 \%$ & $29.0 \%$ & $90.3 \%$ & $9.7 \%$ \\
\hline $31-50$ & $79.5 \%$ & $20.5 \%$ & $94.3 \%$ & $5.7 \%$ \\
\hline $51-65$ & $57.5 \%$ & $42.5 \%$ & $86.7 \%$ & $13.3 \%$ \\
\hline$>65$ & $53.7 \%$ & $46.3 \%$ & $58.5 \%$ & $41.5 \%$ \\
\hline Low income & $23.6 \%$ & $76.4 \%$ & $52.8 \%$ & $47.2 \%$ \\
\hline $\begin{array}{l}\text { Medium } \\
\text { income }\end{array}$ & $58.7 \%$ & $41.3 \%$ & $50.8 \%$ & $19.2 \%$ \\
\hline High income & $59.2 \%$ & $40.8 \%$ & $86.7 \%$ & $13.3 \%$ \\
\hline$<18$ Male & $75.9 \%$ & $24.1 \%$ & $100.0 \%$ & $0.0 \%$ \\
\hline $18-30$ Male & $77.8 \%$ & $22.2 \%$ & $88.9 \%$ & $11.1 \%$ \\
\hline $31-50$ Male & $61.1 \%$ & $38.9 \%$ & $88.9 \%$ & $11.1 \%$ \\
\hline $51-65$ Male & $44.4 \%$ & $55.6 \%$ & $55.6 \%$ & $44.4 \%$ \\
\hline$>65$ Male & $24.4 \%$ & $75.6 \%$ & $64.4 \%$ & $35.6 \%$ \\
\hline$<18$ Female & $66.7 \%$ & $33.3 \%$ & $81.8 \%$ & $18.2 \%$ \\
\hline $18-30$ Female & $81.4 \%$ & $18.6 \%$ & $100.0 \%$ & $0.0 \%$ \\
\hline $31-50$ Female & $54.5 \%$ & $45.5 \%$ & $84.8 \%$ & $15.2 \%$ \\
\hline $51-65$ Female & $60.9 \%$ & $39.1 \%$ & $60.9 \%$ & $39.1 \%$ \\
\hline$>65$ Female & $22.2 \%$ & $77.8 \%$ & $33.3 \%$ & $66.7 \%$ \\
\hline & & & & \\
\hline & & $38.0 \%$ & $82.0 \%$ & $8.0 \%$ \\
\hline
\end{tabular}

Table 4: T-test for equality of means of shorter and longer trips.

\begin{tabular}{|l|c|c|c|c|c|c|c|}
\hline \multirow{2}{*}{ Aspect } & \multirow{2}{*}{ Mode } & \multicolumn{3}{|c|}{ Shorter trips } & \multicolumn{3}{c|}{ Longer trips } \\
\cline { 3 - 9 } & & Means & $\mathrm{t}$ & Sig. & Means & $\mathrm{t}$ & Sig. \\
\hline Travel time & Metro & 4.24 & 9.012 & 0.000 & 4.16 & 6.835 & 0.000 \\
\hline & Tram & 3.08 & & & 3.11 & & \\
\hline Travel cost & Metro & 3.04 & 2.271 & 0.024 & 2.98 & 0.397 & 0.691 \\
\hline
\end{tabular}


Table 4: Continued.

\begin{tabular}{|l|c|c|c|c|c|c|c|}
\hline & Tram & 2.73 & & & 2.91 & & \\
\hline Walking distance & Metro & 3.58 & 0.690 & 0.490 & 3.59 & 0.551 & 0.582 \\
\hline & Tram & 3.49 & & & 3.51 & & \\
\hline Waiting time & Metro & 3.88 & 6.709 & 0.000 & 3.69 & 3.195 & 0.002 \\
\hline & Tram & 3.08 & & & 3.19 & & \\
\hline Air-conditioning & Metro & 3.39 & 6.330 & 0.000 & 3.26 & 5.637 & 0.000 \\
\hline & Tram & 2.56 & & & 2.35 & & \\
\hline Scenery & Metro & 2.06 & -6.617 & 0.000 & 2.19 & -5.337 & 0.000 \\
\hline & Tram & 2.85 & & & 3.00 & & \\
\hline Emotional attachment & Metro & 2.14 & -4.556 & 0.000 & 2.21 & -4.150 & 0.000 \\
\hline & Tram & 2.72 & & & 2.85 & & \\
\hline Crowdedness & Metro & 2.94 & 0.338 & 0.735 & 2.86 & -2.710 & 0.007 \\
\hline & Tram & 2.89 & & & 3.27 & & \\
\hline Service quality & Metro & 3.02 & 3.758 & 0.000 & 2.87 & 0.451 & 0.652 \\
\hline & Tram & 2.55 & & & 2.80 & & \\
\hline $\begin{array}{l}\text { Passenger } \\
\text { announcement }\end{array}$ & Metro & 2.33 & 3.647 & 0.000 & 2.22 & 1.102 & 0.271 \\
\hline & Tram & 1.92 & & & 2.06 & & \\
\hline $\begin{array}{l}\text { Mobile } \\
\text { reception }\end{array}$ & Metro & 2.91 & 4.103 & 0.000 & 2.77 & 1.797 & 0.073 \\
\hline & Tram & 2.33 & & & 2.46 & & \\
\hline Stability & Metro & 3.02 & 2.630 & 0.009 & 2.83 & 0.153 & 0.879 \\
\hline & 2.66 & & & 2.80 & & \\
\hline
\end{tabular}

\section{ACKNOWLEDGEMENT}

The research reported in this paper was supported by the State Administration for Foreign Expert Affairs of China.

\section{REFERENCES}

[1] UITP (Union Internationale du transport public) 2015. Light rail in figures: Statistics Brief. Belgium: Brussels. Downloaded 2017-04-22. URL: http://www.uitp.org/sites/default/files/cck-focus-papers-files/UITP_Statistic_Brief_4p -Light\%20rail-Web.pdf

[2] EMTA (European Metropolitan Transport Authorities), Light Rail Explained. Paris: EMTA, 2014.

[3] Alpkokin, P., Kiremitci, S.T. \& Black, J.A., LRT and street tram policies and implementation in turkish (sic) cities. Journal of Transport Geography, 54, pp. 476487, 2016

[4] Godard, X., Some lessons from the LRT in Tunis and the transferability of experience. Transportation Research Part A-Policy and Practice, 41(10), pp. 891-898, 2007.

[5] Hensher, D.A., Ho, C. \& Mulley, C., Identifying resident preferences for bus-based and rail-based investments as a complementary buy in perspective to inform project planning prioritisation. Journal of Transport Geography, 46, pp. 1-9, 2015. 
[6] Valenzuela-Montes, L.M., Soria-Lara, Julio, A. \& Navarro-Ligero, M.L., Analysing stakeholders' perception of Light Rail Transit as an opportunity to achieve sustainable mobility in Granada (Spain). Journal of Transport Geography, 54, pp. 391-399, 2016.

[7] Hubbell, J. et al. Mode succession in a public transit corridor. 15th International Conference on Urban Transport and the Environment, Bologna, Italy, 22-24 Jun. 2009. WIT Transactions on the Built Environment, 107, pp. 23-34, 2009.

[8] Machado-León, J.L., de Ona, R. \& de Ona, J., The role of involvement in regard to public transit riders' perceptions of the service. Transport Policy, 41, 34-44, 2016.

[9] Zhao, J. et al., Analysis of Metro Ridership at Station Level and Station-to-station Level in Nanjing: An Approach Based on Direct Demand Models. Springer US, 2014.

[10] Wang, W.L., Lo, S.M. \& Liu, S.B., Aggregated metro trip patterns in urban areas of Hong Kong: evidence from automatic fare collection records. Journal of Urban Planning and Development, 141(3), 2015.

[11] Guo, W., Zhang, Y., You, J., Hu, J. \& Pei, X., Travel modal choice analysis for traffic corridors based on decision-theoretic approaches. Journal of Central South University, 23, pp. 3028-3039. 2016.

[12] Feng, S., Shen, X. \& Hu, B., Over-supply in public transportation: case study of bus and metro lines in Harbin City, China. Promet - Traffic \& Transportation, 5, pp. 471477, 2016.

[13] Gu, W., Amini, Z. \& Cassidy, M.J., Exploring alternative service schemes for busy transit corridors. Transportation Research Part B, 93, pp. 126-143, 2016.

[14] Top, H.H., Innovations in tram and light rail systems. Proceedings of the Institution of Mechanical Engineers Part F. Journal of Rail and Rapid Transit, 213, pp. 133-141, 1999.

[15] Wang, Z., Chen, F. \& Xu, T., Interchange between metro and other modes: access distance and catchment area. Journal of Urban Planning and Development, 142(4), 2016.

[16] Sivakumaran, K., Li, Y., Cassidy, M. \& Madanat, S., Access and the choice of transit technology. Transportation Research Part A, 59, 204-221, 2014.

[17] Ettema, D., Gärling, T., Eriksson, L., Friman, M., Olsson, L.E. \& Fujii, S., Satisfaction with travel and subjective well-being: Development and test of a measurement tool. Transportation Research Part F, 14, pp. 167-175, 2011.

[18] Hensher, D.A. \& Mulley, C ., Modal image: candidate drivers of preference differences for BRT and LRT. Transportation, 42, pp. 7-23, 2015.

[19] de Ona, J. et al., Transit passengers' behavioural intentions: the influence of service quality and customer satisfaction. Transportmetrica A-Transport Science, 12(5), pp. 385-412, 2016.

[20] de Vos, J., Mokhtarian, P.L., Schwanen, T., Van Acker, V. \& Witlox, F., Travel mode choice and travel satisfaction: bridging the gap between decision utility and experienced utility. Transportation, 43, pp. 771-796, 2016.

[21] Stradling, S.G., Anable, J. \& Carreno, M., Performance, importance and user disgruntlement: a six-step method for measuring satisfaction with travel. Transportation Research Part A, 41, 98-106, 2007

[22] Fan, Y., Guthrie, A. \& Levinson, D. Waiting time perceptions at transit stops and stations: Effects of basic amenities, gender, and security. Transportation Research Part A, 88, pp. 251-264, 2016.

[23] Moreau, A., Public transport waiting times as experienced by customers. Public Transportation International, 41(3), pp. 52-71, 1992. 
[24] Tyrinopoulos, Y. \& Constantinos, A., Public transit user satisfaction; variability and policy implications. Transport Policy, 15, pp. 260-272, 2008.

[25] Anable, J. \& Gatersleben, B., All work and no play? The role of instrumental and affective factors in work and leisure journeys by different travel modes. Transportation Research Part A, 39, pp. 163-181, 2005.

[26] Zacharias, J. \& Li, X., Shifting from metro to sustainable surface modes for shortdistance travel. Transportation Research Record, 2541, pp. 38-45, 2016.

[27] Friman, M., Edvardsson, B. \& Gärling, T., Frequency of negative critical incidents and satisfaction with public transport services - I. Journal of Retailing and Consumer Services, 8, pp. 95-104, 2001.

[28] Friman, M.\& Gärling, T., Frequency of negative critical incidents and satisfaction with public transport services - II.Journal of Retailing and Consumer Services, 8, pp. 105$114,2001$.

[29] Hong Kong 2016 Annual Transport Digest; Transport Department, Government of HKSAR, Online, http://www.td.gov.hk/mini_site/atd/2016/en/section5_2.html. Accessed on: 27 Apr. 2017. 